\title{
Effect of Gusty Wind on Road Tunnel Safety
}

\author{
Aleš Suban* - Stojan Petelin - Peter Vidmar \\ University of Ljubljana, Faculty of Maritime Studies and Transport, Slovenia
}

This article deals with the effect of wind with its characteristics on the longitudinal ventilation of a road tunnel as a key segment of fire safety. Using CFD simulations, the influence of wind gusts, which differ and is more difficult to define than the influence of a constant wind on tunnel ventilation, is researched in more detail. On the basis of the simulation results, which have been validated with real measures, the findings are presented regarding the importance of taking into account the characteristics of non-stationary wind to ensure the adequate safety of tunnel users in the event of a fire, as well as of fire-fighting units during intervention.

Keywords: road tunnel, Kastelec tunnel, longitudinal ventilation, wind gusts, the Bora wind, CFD simulations

Highlights

- $\quad$ The Bora wind characteristics that have an effect on road tunnel ventilation are defined.

- Composition of CFD model in FDS by taking into account the wind characteristics is presented. For case study the Kastelec motorway tunnel is used.

- $\quad$ Results present the importance of taking wind gustiness into account when designing and managing the tunnel ventilation as a segment of road tunnel safety.

- For model validation real measurements of gusty wind Bora and air speed in Kastelec tunnel are used.

\section{INTRODUCTION}

Tunnels are strategic structures that, predominantly in hilly terrain, enable adequate, safer, and faster transport connections. All newly constructed tunnels in Slovenia, as in the rest of the European Union (EU), that are longer than $500 \mathrm{~m}$ must be constructed in accordance with the EU Directive 2004/53/EC, which determines the minimal safety requirements for tunnels in the Trans-European Road Network. The directive specifies the minimal requirements for tunnels, which they must ensure the control of emissions that are created due to the vehicles, as well as control of the extraction of smoke and heat in the event of a fire. Mechanical ventilation must provide the adequate extraction of smoke and heat, visibility, decrease the spreading of the fire, as well as provide adequate conditions for fire-fighters, so that they are able to gain access to extinguish any fires and to rescue people from the tunnel [1] and [2]. Ventilation of unidirectional motorway tunnels is predominantly implemented longitudinally in the direction of the traffic flow, while some longer tunnels utilise combined ventilation [2] and [3]. Winds that blow on the tunnel's portal either help or hinder mechanical ventilation. When the wind is blowing in the opposite direction to the direction of the ventilation it can cause problems with ensuring adequate air velocities to adequately ventilate the tunnel, as it opposes the thrust of the ventilators.
The effect of the wind on the safety of the road tunnel must be taken into account when designing the ventilation, as well as during its subsequent use. A number of tunnels in the Slovenian motorway network face the problem of wind effect; these are the Kastelec tunnel, the Dekani tunnel, and the Markovec tunnel. They latter lie in very windy areas where powerful gusts from the Bora wind blow, in addition to which, the direction of the portals is in the same direction as the wind. The Bora wind, due to its high velocity gusts, effects the ventilation of the tunnels [1].

When designing and finding solutions for the ventilation of tunnels that are affected by winds, it is necessary to take into account the wind's characteristics. In the ensuing article it shall be proven that, gustiness as a characteristic of the wind, should be taken into consideration when designing the ventilation. This paper uses the Kastelec tunnel as a case study where the issue of strong gusty wind which affects the tunnel's portal is dealt with. The ventilation in the Kastelec tunnel is longitudinal and is under effect of gusty Bora wind with speeds up to $25 \mathrm{~m} / \mathrm{s}$, which covers approximately $90 \%$ of windy days in the year [1]. In rare cases, in approximately $8 \%$ of days in the year, the Bora wind gusts reach speeds of up to $30 \mathrm{~m} / \mathrm{s}$ or more [1]. In these cases, traffic flow through the tunnel is foreseen to be halted, as it's predicted that the effect of the wind on the ventilation is such that smoke and heat could not be properly extracted in the event of fire. 


\subsection{Adequate Ventilation in Road Tunnels as a Safety Segment}

Adequate ventilation that extracts smoke and heat in the event of a fire is essential for ensuring the safety of road tunnel users [3] and [4]. We need to ask ourselves, how can we determine that the tunnel ventilation is adequate in the event of a fire, when is effected by wind? In literature [4] and [5] is stated that the ventilation must extract the smoke and heat in the event of a fire to ensure the safe conditions for the users to exit the tunnel as well as to allow effective fire-fighting operations [6]. The ventilation must fulfil this requirement even under various meteorological influences [1] and [6]. Which is why, the tunnels that are affected by wind must have increased capabilities as well as adequate ventilation management so that the effect of the wind is eliminated.

The release of heat and the creation of smoke depend on a fire's intensity. If the longitudinal ventilation velocity in unidirectional road tunnels in the direction of the traffic flow is too low, lower than that of the spreading smoke, the smoke will travel against the direction of the ventilation flow, also known as back-layering [2] to [5] and [7]. Back-layering endangers both the tunnel users and fire-fighters. Smoke contains numerous toxic combustion products, has a high temperature, and reduces visibility. It hinders, and in some cases makes successful interventions by fire-fighters impossible [6].

The critical velocity $u_{c}$ of the air in the tunnel is defined as the minimal wind velocity required to prevent the back-layering of smoke [2], [3] and [7]. The critical velocity depends on the geometry of the tunnel [2] and [7], and the size of the fire (HRR) [3]. Generally, the critical velocity in tunnels is approximately up to $2 \mathrm{~m} / \mathrm{s}$ for smaller vehicle fires or initial fires (up to $10 \mathrm{MW}$ ), 2 to $3 \mathrm{~m} / \mathrm{s}$ for fires of lorries carrying cargo (30 to $50 \mathrm{MW}$ ) and does not exceed 4 $\mathrm{m} / \mathrm{s}$ for fires of tankers carrying fuel (above $100 \mathrm{MW}$ ) [1] and [3]. On the basis of this, we can establish that longitudinal tunnel ventilation ensures adequate safety for tunnel users and fire-fighter interventions if the ventilation speed is greater than the critical velocity of a certain intensity of fire in order to prevent backlayering [2] to [7]. As an example, if the possibility of an approximately $30 \mathrm{MW}$ fire is foreseen, the tunnel ventilation must ensure an air velocity of above $3 \mathrm{~m} / \mathrm{s}$ even under windy conditions.

\section{WIND CHARACTERISTICS}

The effect of wind that has a constant velocity is not the same as that of gusty wind. It is easier to predict the tunnel conditions with wind with a constant velocity while also being easier to study its effect. The velocity hardly changes over time, making it possible to determine the pressure that the wind establishes on the tunnel's portal, which is a measure of the pressure that the mechanical ventilation must provide. On the other hand, the velocity of gusty wind varies considerably over time. At the peak of a gust, the velocity can reach 3 to 4 times the average, while a period of almost still air can immediately follow.

The prevalent winds above the moderate geographical latitudes and in the altitudes over Europe are westerly winds. From a general westerly direction, the flow veers to the north and south, while large, closed spiralling winds occasionally break away. These are more common in the lower levels of the atmosphere and are known as cyclones and anticyclones. In relation to the weather conditions elsewhere in Europe, the winds in Slovenia are relatively weak, and when they are strong, they are both temporally and spatially restricted [8]. Regional winds are winds whose area of occurrence is in the range of approximately $100 \mathrm{~km}$ in size and are a consequence of general winds. In Slovenia, the Alpine and Dinaric mountain barriers have an effect on them. Close to the ground there are three distinct wind regimes: sirocco (a southerly wind), the Bora wind, and Karavanke foehn [8].

According to characteristics, winds are classified into steady, gusty and spiralling winds (whirlwinds) [8].

Steady winds blow at a constant velocity, which means they do not have gusts. The winds form and blow in flat areas where there are fewer obstacles and friction. They have smaller velocity oscillations during their constant average velocity, which, if present, are smaller and short-lasting with speeds around the average. Examples of such types of winds in Slovenia are the sirocco and thermal winds of the mistral, burin, etc. [8]. Whirlwinds are a rare phenomenon, occurring predominantly during severe storms. They are a weaker form of tornado. The wind direction is a spiral around the centre due to large differences in pressure, the velocities reached are therefore very high, while the surface area is small. In Slovenia, whirlwinds are very rare phenomenon, mainly occurring on the surface of the sea and lasting only a very short time [8]. 


\subsection{Gusty Winds}

A gust of wind is defined as a fast, strong, and abrupt rush of wind for a short time period which is usually followed by a period of still air [8] and [9]. Gusts are predominantly short-lived, lasting 20 to 50 seconds. A good example of gusty wind is the Bora wind which blows in the areas of SW Slovenia. The characteristics of the Bora wind are described below to get a sense of the gusty winds that are the subject of this study. Gusty winds form mainly due to the difference between air pressures in more hilly areas. The equalisation of these pressures leads to gusts forming.

The Bora wind is cold, dry, and very gusty. A strong Bora wind is a regional phenomenon that is most prominent on slopes and just beneath them, as well as where converge and gather speed [8]. The Bora wind usually blows in a stable atmosphere (cold air pushes through under the warm air) which means that the local Bora wind speeds can greatly increase due to the convergence of winds between landforms, while there are also sheltered areas [8]. The Bora wind is dangerous due to its powerful gusts that effect traffic, structures and vegetation. The development of the Bora wind to its full intensity is relatively fast. In most cases, the Bora wind can develop from low intensity initial individual gusts to full intensity in 20 minutes on average; exceptional cases are also possible, where the Bora wind reaches its highest values in its initial gusts [9]. The average duration of the Bora wind is one day, but cases have been seen where it lasts for 12 days.

One must be careful when using the average velocity of gusty wind like the Bora. An important characteristic of the Bora wind is its gustiness; measurements with a precise anemometer show almost still air between individual gusts [9]. Due to these periods of still air, the average velocity is low, however its gusts can reach three to four times its average speed [9], which is also confirmed by the measurements [10] and [11]. This is why one must take into account the high velocity of a gust when calculating the effects of gusty wind.

From experience and measurements done in the north Adriatic, strong gusts of the Bora wind repeat in periods from 3 to 4 minutes (sometimes up to 11 minutes) [9]; measurements taken in the Karst region of Slovenia [10] prove the same. On the basis of analyses of Bora measurements [9] to [11] and its varying gust intensities (velocities), a simple and important Bora wind pattern could be created for research presented in this article (Fig. 1). The form of the gust is clearly visible from the pattern (the full line). A gust can emerge relatively quickly and then subside, it can also occur gradually and subside quickly, or occur gradually and subside gradually. Until the next gust, a period of almost still air occurs, or a period with very low wind velocities. Regardless of the form of the gust, we can conclude that is occurs quickly and subsides quickly.

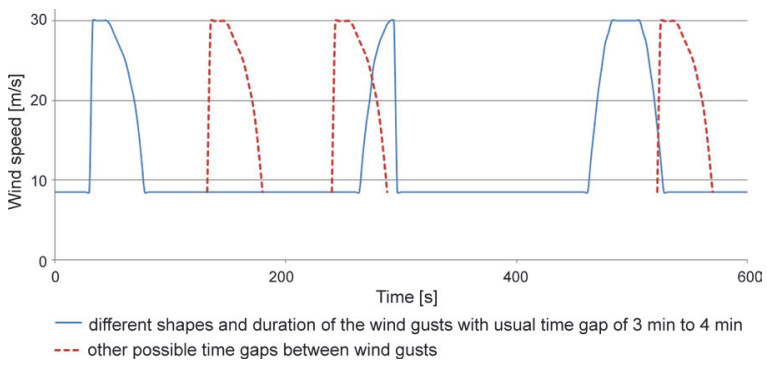

Fig. 1. Gust patterns of the Bora wind

The form itself is not an essential characteristic of the effect of a gust of wind. The characteristics that significantly affect the environment, traffic and, in our case, road tunnel ventilation are:

- Gust intensity - the highest velocity reached by the wind during a gust. The Bora wind can reach speeds of up to $50 \mathrm{~m} / \mathrm{s}$ in exposed areas [9] and [11].

- The duration of a gust - the length of time the gust lasts. Bora wind gust last between $20 \mathrm{~s}$ and $60 \mathrm{~s}$ [9] and [10]. The various gust durations are shown in Fig. 1 (the full line). The most frequent duration of gusts is around $30 \mathrm{~s}$ to $40 \mathrm{~s}$, while shorter gusts are more frequent than longer ones [9].

- Period between individual gusts - the interval between gusts. Typical periods of stronger Bora gusts range from $3 \mathrm{~min}$ and $11 \mathrm{~min}$ [9] and [10].

\section{COMPOSITION OF THE CFD MODEL}

Using computer generated models, the tunnel with its characteristics and ventilation can be modelled. The boundary and initial conditions are used to model the effect of wind on the tunnel's ventilation. The use of simulation tools allows us to study the problem of the effect of winds on tunnel ventilation in more detail, taking into account that the person has to construct the model correctly. Researches described in this article define the significance of the problem, the approach to solving it, as well as the characteristic and specifics that are necessary to be considered.

Simulation models that can be used to study and analyse the field of road tunnel ventilation can be 
roughly divided into zone models, one-dimensional (1D) models and three-dimensional (3D) models, to which apply the principle of computational fluid dynamics (CFD). CFD models are most suitable for carrying out studies regarding the effects of winds and other meteorological phenomenon on tunnel ventilation. Models that are based on CFD are being used more and more often. The numerical solving of the system of partial differential equations, which describe the physical behaviour of the flow give a better understanding of the underlying laws of fluid flow. Models can be based on various methods: the relatively simple RANS (Reynolds-averaged NavierStokes) and TRANS (transient RANS) models appropriate for very large systems like tunnels [12]; the large eddy simulation (LES) method that utilises turbulent models with which to deal with larger systems with good accuracy, so the method is very appropriate for the tunnels [13]; the most accurate model that is direct numerical simulation (DNS) which is an exceptionally demanding method to solve and it is only used for very small systems and not so much for the tunnels.

The fire dynamics simulator (FDS) program which was used for research in this article is based on the LES method. The software was conceived at the American National Institute for Standards and Technology (NIST). It comes with the FDS Smokeview (FDS-SMV) companion visualisation program that enables the graphic display of geometries and calculated parameters from the FDS program. FDS is a suitable program to explore the presented problem of the effect of winds and to carry out simulations. It enables CFD simulations, the input model with boundary pressure conditions with which the gust of wind can be modelled, and includes a combustion model to describe the fire.

The Governing equations for FDS model are for conservation of mass (Eq. (1)), momentum (Eq. (2)) and energy (Eq. (3)) for a Newtonian fluid and are presented in [14] in detail:

$$
\begin{gathered}
\frac{\partial \rho}{\partial t}+\nabla \cdot \rho \mathbf{u}=\dot{m}_{b}^{\prime \prime \prime}, \\
\frac{\partial}{\partial t}(\rho \mathbf{u})+\nabla \cdot \rho \mathbf{u} \mathbf{u}+\nabla p=\rho \mathbf{g}+\mathbf{f}_{b}+\nabla \cdot \tau_{i j}, \\
\frac{\partial}{\partial t}\left(\rho h_{s}\right)+\nabla \cdot \rho h_{s} \mathbf{u}=\frac{\mathrm{D} p}{\mathrm{D} t}+\dot{q}^{\prime \prime \prime}-\dot{q}_{b}^{\prime \prime \prime}-\nabla \cdot \dot{\mathbf{q}}^{\prime \prime \prime}+\varepsilon,
\end{gathered}
$$

where $\dot{m}_{b}^{\prime \prime \prime}$ is the production rate of species by evaporating droplets or particles, $t$ is time, $\rho$ is density and $\mathbf{u}$ is the velocity vector (Eq. (1)). The term $\mathbf{u u}$ in momentum equation (Eq. (2)) is a dyadic tensor, $\mathbf{g}$ is gravity vector, $\mathbf{f}_{b}$ represents external forces (i.e. drag exerted by liquid droplets) and $\tau$ is the viscosity stress tensor. In energy conservation equation (Eq. (3)), $h_{s}$ is sensible enthalpy, $\dot{q}^{\prime \prime \prime}$ is heat release rate per unit volume from a chemical reaction, $\dot{q}_{b}^{\prime \prime}$ is the energy transferred to the evaporating droplets, $\dot{\mathbf{q}}_{b}^{\prime \prime \prime}$ represents the conductive and radiative heat fluxes and $\varepsilon$ is the dissipation rate.

Turbulence is treated by means of the Smagorinsky form of Large Eddy Simulation (LES) as a default mode of operation [14]. FDS uses rectangular grid elements and the core algorithm is an explicit predictor-corrector scheme that is second order accurate in space and time [14]. Hydrodynamic model solves numerically an approximate form of the Navier-Stokes equations, appropriate for low speed and thermally-driven flow. The approximation involves the filtering out of acoustic waves [14].

The literature [14] also contains a detailed description of the numerical solution of the momentum and pressure equations and for that, it is sufficient to consider the momentum equation written as [14]:

$$
\frac{\partial \mathbf{u}}{\partial t}+\boldsymbol{F}+\nabla \mathcal{H}=0
$$

The pressure equation is obtained by taking the divergence of the momentum equation [14]:

$$
\nabla^{2} \mathcal{H}=\frac{\partial}{\partial t}(\nabla \cdot \mathbf{u})-\nabla \cdot \mathbf{F}
$$

For the outflow, pressure is defined by $\mathcal{H}=q^{2} / 2+\tilde{p} / \rho$, where $q \equiv|\mathbf{u}|$ and $\tilde{p}$ is set to $\tilde{p}_{\text {ext }}$ [14]. External pressure $\tilde{p}_{\text {ext }}$ on an open vent can be set by the user (DYNAMIC_PRESSURE; by default it is set to 0 ). For the inflow, when fluid enters the domain at an open boundary condition, it is assumed that the Bernoulli equation is valid and that the fluid on the boundary accelerates from the state along a streamline [14].

The FDS software is often used to solve problems in tunnels like smoke spread and air velocity in case of fire [15] and [16], reconstruction of tunnel fires to evaluate the conditions likely to be found in this type of fires [17], clarification of some fire phenomena, for example pulsation of a tunnel fire [18], and for numerical simulation of real scale fire tests [19]. FDS is validated by the developers of the software [20]. Various other researchers have also validated the software for different convection flows [21], for fires in buildings [22] as well as for tunnel fires [23]. 
When a simulation CFD model starts being constructed, it is important that the model is constructed gradually. Beginning with simple inputs, it then slowly evolves into a more complex model that describes the real situation. The optimum between accuracy, calculation time, and costs must be found. By taking into account the wind characteristics, it is possible to contribute to the planning of tunnel ventilation and increasing the safety level. By using CFD simulation tools, we are able to perform analyses in which the analyser must take certain rules into account in order to ensure the most realistic results.

As already mentioned in the introduction, the research of wind issue is most easily presented using an actual case study of a tunnel, where we present the importance of taking the wind characteristics into account. In the case study it is shown what was considered when carrying out the simulations. Characteristics of the Kastelec tunnel will be used: the geometry, ventilation, and wind characteristics of the Bora wind that blows at the location of the tunnel. The tunnel is suitable as a case study, as the geometry of the tunnel is like the majority of newly built motorway tunnels in Slovenia, while similarities can be found to many other motorway tunnels in the EU. The same applies to the supervision, managing, and machinery of the tunnel.

\subsection{Tunnel Geometry and Fire Modelling}

In the simulation model, the geometry must be properly designed (a good approximation of the real situation), adequate initial and boundary conditions must be set. The FDS enables the modelling of a fire, where it is possible to describe using a suitable combustion model or as a source of heat and mass. The second approach is usually more simple and suitable for the field dealt with. As we focus on the effect of winds on ventilation, the actual development of the fire is not significant, as the formation of smoke and heat release is greatest with a fully developed fire. If the ventilation adequately extracts the smoke and heat of a fully developed fire, it will also do so with a less intense fire. This is why we model the intensity of a fully developed fire in the tunnel. The intensity of the fire is predominantly determined using the heat release rate (HRR), measured in $\mathrm{kW}$ or MW. In the model, we determine the location of the fire and set it as the heat and substance source of certain intensity HRR of a fully developed fire. This is done by determining the HRR per unit area.

The Kastelec tunnel is constructed as a two-lane twin-tube tunnel with pavements, passageways, and emergency lay-bays. Including the portals, the left tube - direction Koper - Ljubljana (KP-LJ) - which is used in this research is $2320 \mathrm{~m}$ long. The width of an individual tunnel tube is $9.60 \mathrm{~m}$ and the height is $6.5 \mathrm{~m}$. Both tubes are connected with passageways every $400 \mathrm{~m}$. By taking into account the horizontal course of the track, the maximum cross slope of the road is determined at $2.5 \%$. The geometry described is created in the simulation model. In simulation, a section of tunnel $400 \mathrm{~m}$ long ( $x$-axis), $9 \mathrm{~m}$ wide ( $y$-axis) and $6.5 \mathrm{~m}$ high (z-axis) is used (Fig. 2). There were 64800 cells used in numerical study. Mesh distribution in $x$-axis is 400 cells, in $y$-axis 18 cells and $z$-axis 9 cells (Fig. 2). By using a section of the tunnel, we can lower the number of cells, which drastically cuts the calculation time. Regarding the size of the section, it must not be too small, and it must enable the fluid flow to develop properly. If not, the results will not be accurate enough. Vehicles that may be present in the tunnel are not considered, as their type and number cannot be foreseen.

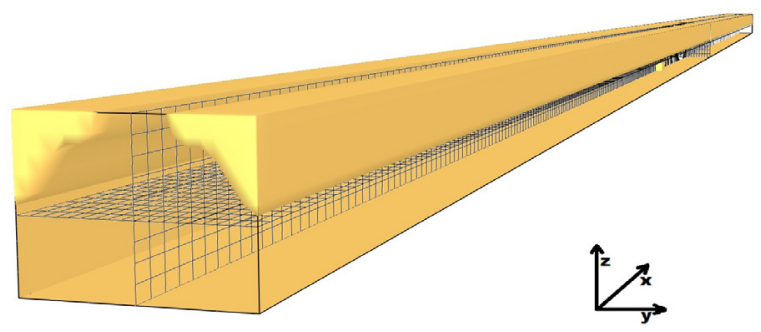

Fig. 2. Mesh distribution and computational domain geometry

Grid independence study was done for numerical study with finer cells throughout the domain (108000 cells) and the results for the ventilation speed in tunnel tube were almost the same through both simulations, only at few points the maximum differences were less than $1.2 \%$. This is a satisfactory outcome for the reduction of computational time and does not affect the findings of the final results.

In the tunnel, forced longitudinal ventilation with axial fans is foreseen for the right and left tunnel tube. Since the direction of the prevailing wind - the Bora wind - coincides with the longitudinal position of the tunnel tubes, its effect is favourable on the tunnel tube leading from LJ to KP and unfavourable in the direction from KP to LJ. To maintain longitudinal ventilation in the direction of traffic in the KP-LJ tunnel pipe considering the wind velocity of $25 \mathrm{~m} / \mathrm{s}$ in the opposite direction, 14 fans are required for normal operation, which are positioned in pairs every $100 \mathrm{~m}$ between fans and $150 \mathrm{~m}$ from portals (Fig. 3). Every jet fan provides $1100 \mathrm{~N}$ of thrust in the main direction. 
In exceptional cases, wind velocities of more than 30 $\mathrm{m} / \mathrm{s}(108 \mathrm{~km} / \mathrm{h})$ can occur, which equate to $8 \%$ of windy days in a year, where the closure of the tunnel is foreseen. It should be mentioned that in the ventilation project, the wind pressure on the portal at $25 \mathrm{~m} / \mathrm{s}$ is foreseen to be constant; however the Bora wind blows in gusts. All ventilators are foreseen to operate at full power during periods of maximum wind velocities to overcome its effects.

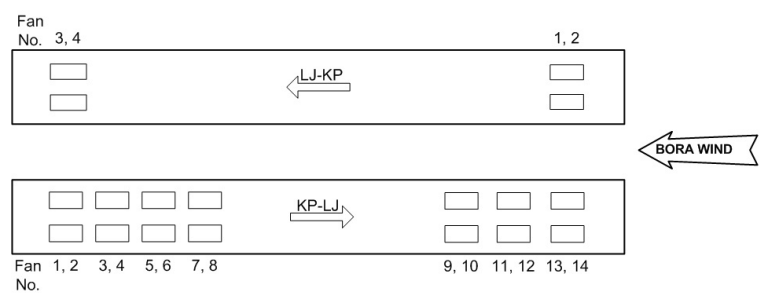

Fig. 3. Layout of fans in the Kastelec tunnel

\subsection{Boundary Conditions and Accounting for the Wind}

Boundary conditions are defined as pressures, temperatures, densities, velocities, and surface characteristics. The beginning and end of the tunnel geometry is defined as an open boundary condition, which does not represent an obstacle in the flow, and the remaining surfaces as walls. For air (gas) movement in the tube pressure boundary conditions are used: on the one side, pressure created by the fans, on the other side, pressure caused by a gust of wind. Pressure loss that occurs along the length of the tunnel is taken into account. Boundary condition 1 is the pressure exerted on the starting point of the section marked as $p_{1}$ and is the pressure caused by all the fans in the tunnel, less the losses in the tunnel tube. Boundary condition 2 is the pressure on the final point of the geometry, marked with $p_{2}$ and is the pressure caused by the wind (Bora) blowing in the opposite direction to the ventilation, less the losses in the tunnel tube (Fig. 4).

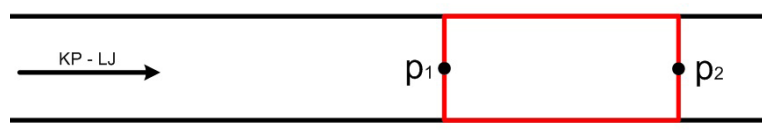

Fig. 4. The tunnel section with pressure boundary conditions

Equation for calculating the pressure for boundary condition 1:

$$
p_{1}=p_{a}+n_{f} \cdot p_{f}-p_{\text {loss }},
$$

where $n_{f}$ is the number of fans, $p_{f}$ is the pressure of an individual fan, whereby it is considered that all fans provide the same pressure, the equation is presented in [3]; $p_{\text {loss }}$ are pressure losses in the tube calculated using the Darcy equation. The surface roughness (friction coefficient) is accounted for in the losses, which also takes into consideration the various construction obstacles present in the tunnel. Stationary vehicles are not taken into consideration as their type and number are difficult to predict. Although, stationary vehicles would represent an obstacle in the flow of both the mechanical ventilation and the wind, which would mean that it would affect both boundary conditions. Atmospheric pressure $p_{a}$ needs to be considered in the event it differs at both ends of the tunnel tube. This primarily occurs in longer tunnels. If the atmospheric pressure is equal at both ends of the tunnel, it can be left out of the calculation of both boundary conditions.

Equation for calculating the pressure for boundary condition 2:

$$
p_{2}=p_{a}+p_{w}-p_{w l o s s},
$$

where $p_{w}$ is dynamic pressure caused by wind, $p_{\text {wloss }}$ is the loss of pressure in the tube during various wind velocities at the portal. Since gusty wind is being considered, the speed on the portal is not constant but varies over time, which must be accounted also for losses. The same is valid for atmospheric pressure $p_{a}$ as is for boundary condition $p_{1}$.

The dynamic wind pressure $p_{w}$ on the portal is calculated using the Eq. (8):

$$
p_{w}=\zeta \frac{\rho u_{w}^{2}}{2},
$$

where $\zeta$ is the coefficient of local loss regarding the shape of the entrance of the tunnel tube (portal), the values range between 0.5 and 1.0 ([3] and [24]) during winds that work directly in the direction of the tunnel, perpendicularly to the portal. In cases where the wind is not directly perpendicular to the portal, the coefficient can be greater than $1 . \rho$ is the air density, $u_{w}$ is the wind velocity at the tunnel portal. Very similar equations for boundary conditions are presented in literature [25], only this ones are moderated for the system dealt with.

The maximum gust velocity of the Bora wind used in the simulation was $30 \mathrm{~m} / \mathrm{s}$. In view of the gust characteristic (Fig. 1), an input model was constructed for boundary condition $2\left(p_{2}\right)$. The velocities were recalculated into pressures which were then entered into the simulation input model (Fig. 5). Calculated and used pressures for boundary condition 1 in simulation was $46 \mathrm{~Pa}$, and for boundary condition 2 at maximum gust speed $30 \mathrm{~m} / \mathrm{s}$ was $59 \mathrm{~Pa}$. It is important 
to know that the duration of gust's maximum speed is just a few seconds. For the example we take a gust of $40 \mathrm{~s}$ which was used in one of the simulation scenarios: the maximum speed emerges quickly in 1 $\mathrm{s}$, lasts for $10 \mathrm{~s}$, then in next $18 \mathrm{~s}$ drops to $83 \%$ of maximum speed, in another $10 \mathrm{~s}$ drops to $66 \%$ and after that drops quickly in $2 \mathrm{~s}$ to the low wind velocity of $27 \%$ of maximum speed until the next gust appears. For longer gusts, percentages were the same, just to each segment of the time additional few seconds were added.

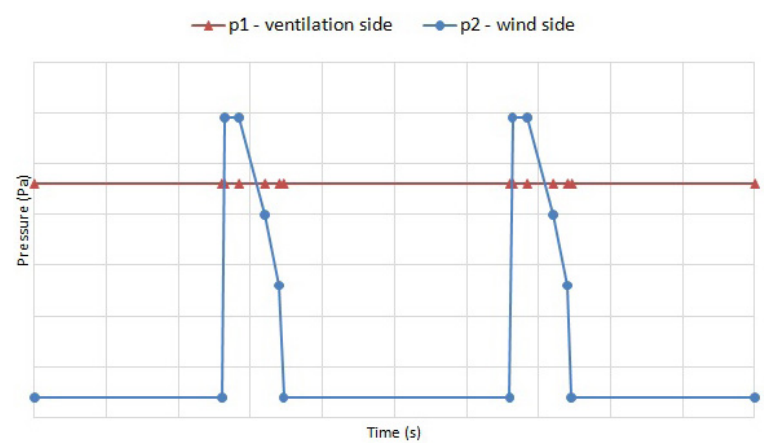

Fig. 5. Example of input model for boundary conditions $p_{1}$ and $p_{2}$ in scenario with two wind gusts of high speed

\section{TUNNEL VENTILATION AND EFFECT OF GUSTY WIND}

\subsection{Simulation Scenarios}

Using numerous simulations of the effect of wind of tunnel ventilation, the field was carefully studied. Many combinations were simulated, using various wind velocities, different amounts of gusts, various forms of gusts, gust durations, periods between gusts, and various fire intensities. Models using constant winds were constructed for comparison. It immediately became clear that the gust's form does not have a significant function, which is why all gusts were modelled in accordance with the $p_{2}$ boundary condition in Fig. 5. On the basis of all the scenarios, a few key ones were chosen and presented. All scenarios also simulate a fire of $10 \mathrm{MW}$, except Scenario 6 in which the fire size is $15 \mathrm{MW}$.

The key wind scenarios were the following:

- Scenario 1: 2 gusts of wind at $30 \mathrm{~m} / \mathrm{s}$, duration of gust 40 seconds, period between gusts 3 minutes (usual Bora wind pattern).

- Scenario 2: 3 gusts of wind at $30 \mathrm{~m} / \mathrm{s}$, duration of gust 40 seconds, period between gusts 1 minute (very rare Bora wind pattern).
- Scenario 3: 2 gusts of wind at $30 \mathrm{~m} / \mathrm{s}$, duration of gust 50 seconds, period between gusts 1 minute (rare Bora wind pattern).

- Scenario 4: 2 gusts of wind, $1^{\text {st }}$ at $30 \mathrm{~m} / \mathrm{s}, 2^{\text {nd }}$ at $27 \mathrm{~m} / \mathrm{s}$, duration of gust 50 seconds, period between gusts 1 minute (usual Bora wind pattern).

- Scenario 5: effect of constant wind at $21 \mathrm{~m} / \mathrm{s}$ (comparison).

- Scenario 6: 2 gusts of wind at $30 \mathrm{~m} / \mathrm{s}$, duration of gust 50 seconds, period between gusts 1 minute, fire HRR is $15 \mathrm{MW}$ (comparison between fire sizes).

\subsection{Results}

To determine the effect of wind on the tunnel's ventilation, six scenarios were constructed which were then analysed using FDS simulation tools. The most important characteristics of gusty wind were divided in the scenarios, such as the period between gusts, length of the gust and its intensity. To compare effects, scenario with a constant wind was also constructed. The results showed that the effect of gusty wind differs from the effect of constant wind.

Results has shown that even in the event when the pressure of the gust on the portal is somewhat greater than the mechanical ventilation pressure, the extraction of smoke and heat from the tunnel may be suitable because of shortness of the gust. This is a consequence of the air flow inertia due to mechanical ventilation. In Fig. 6, the speed of velocities in the tunnel tube in various scenarios is shown, as well as for critical velocities $u_{c}$ for particular fire intensities.

In the most common Bora wind pattern (Scenario 1 ), the speed of the tunnel ventilation remains above 4 $\mathrm{m} / \mathrm{s}$, which ensures the adequate extraction of smoke and heat for modelled fire. In the rare occurrences of more than one strong consecutive gusts (Scenario 2) between which the period is short (1 minute), the interaction of gusts can be seen as well as a greater drop in ventilation velocity. Despite this, the extraction of smoke and heat is appropriate for lower to medium intensity fires.

The gusts are predominantly short-lived (to 40 $\mathrm{s}$ ), in rare cases they can last longer and vary between $50 \mathrm{~s}$ and $60 \mathrm{~s}$. Scenario 3 describes the occurrence of longer gusts of Bora wind, lasting $50 \mathrm{~s}$ with a period of 1 minute. In this case, speed in tunnel tube drops at lowest point of all the scenarios, but still remains above $3 \mathrm{~m} / \mathrm{s}$, which ensures the adequate extraction of smoke and heat at $10 \mathrm{MW}$ fire. Real cases of two or three consecutive gusts of exactly the same intensity are very rare with the Bora wind. That is why a 


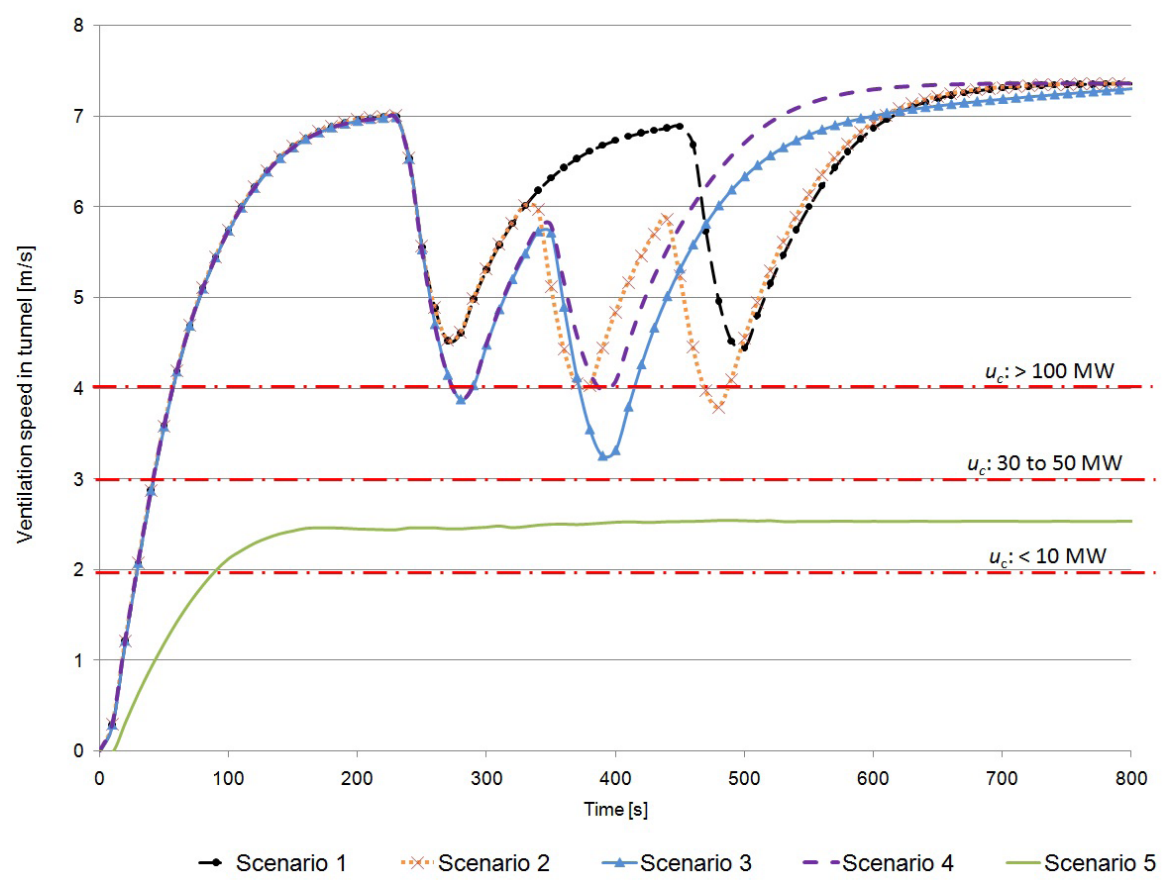

Fig. 6. The results of various wind scenarios for a $10 \mathrm{MW}$ fire

comparison of a more realistic situation was carried out (Scenario 4), where the consecutive gusts differed slightly regarding velocity. In Scenario 4, a model was constructed of the effect of two longer gusts (50 s) with a period of 1 minute, and with varying speeds. The second gust was $3 \mathrm{~m} / \mathrm{s}$ slower that the first. From the result in Fig. 6, there is a visible difference of the effect on the speed in the tunnel in comparison with Scenario 3 in which speed of both wind gusts is equal.

In Scenario 5, constant wind speeds that affect the portal is taken into consideration. The velocity in the tunnel does not fluctuate when affected by constant wind on the portal. Therefore, it is visible in Fig. 5 that even at a much lower velocity of 21 $\mathrm{m} / \mathrm{s}$, the critical velocity of the $10 \mathrm{MW}$ fire is almost

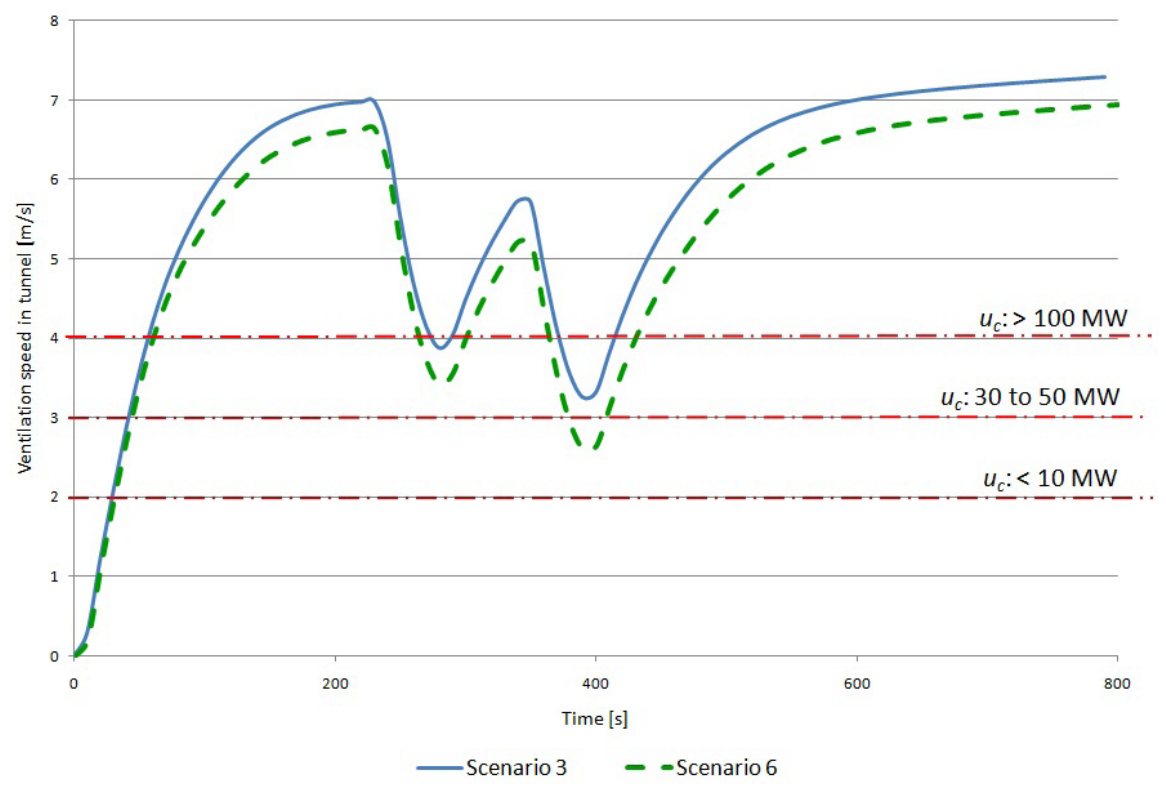

Fig. 7. The difference between $10 \mathrm{MW}$ and $15 \mathrm{MW}$ fire 
reached. At higher speed than $21 \mathrm{~m} / \mathrm{s}$, the tunnel can be established to not provide adequate smoke and heat extraction, as the velocity in the tunnel drops below the critical velocity of a $10 \mathrm{MW}$ fire, that is under 2 $\mathrm{m} / \mathrm{s}$.

In Scenario 6, the wind characteristics are the same like in Scenario 3, but fire has a larger HRR of 15 MW. Results are seen in Fig. 7. The speed in Scenario 6 drops slightly under critical velocity of $15 \mathrm{MW}$ fire for a short period of time, which causes a very short back-layering. The entire occurrence in tunnel lasts $70 \mathrm{~s}$ and is quickly eliminated by the mechanical ventilation (Fig. 8). The smoke remains stratified during this period, while the velocity in the lower part of the tunnel where the users, and later firefighters, are located adequately extracts the smoke and heat (Fig. 8). With comparison between Scenario 3 and Scenario 6 we can see that is important to determine to what size of the fire the ventilation fulfil the safety requirement for a tunnel under various wind influences.

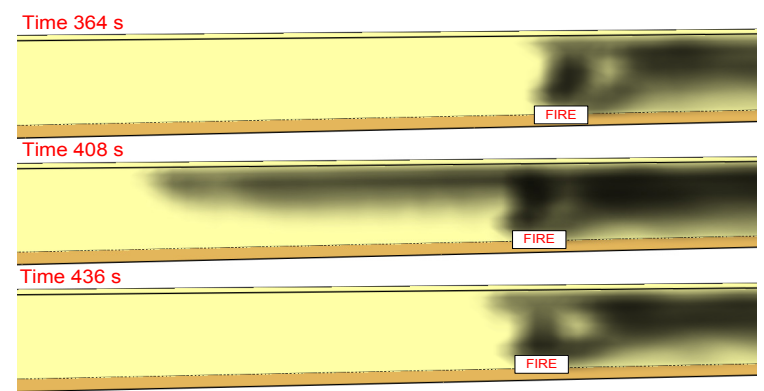

Fig. 8. Short-term back-layering in Scenario 6

\section{VALIDATION OF THE RESULTS WITH MEASUREMENTS}

Verification of the constructed theoretical scenarios was created using real measurements. The Motorway Company of the Republic of Slovenia (DARS), which is the manager of the Slovenian motorway network, carries out meteorological measurements in the area of the Kastelec tunnel, more specifically on the Smelave viaduct [11]. In the Kastelec tunnel itself, air velocity meters are fitted in the tunnel pipe [26]. The wind speed sensor (Boschung Mecatronic WG/WR) accuracy is $\pm 3 \%$ in measuring range from $0.5 \mathrm{~m} / \mathrm{s}$ to $50 \mathrm{~m} / \mathrm{s}$, the tunnel tube air speed sensor (SICK Flowsic 200) typical accuracy is $\pm 0.1 \mathrm{~m} / \mathrm{s}$ in measuring range $-20 \mathrm{~m} / \mathrm{s}$ to $+20 \mathrm{~m} / \mathrm{s}$. A theoretical CFD validation model was constructed on the basis of real measurements [11] and [26]. The CFD model characteristics were the same as in the tunnel at the time of measuring: wind in gusts of $30 \mathrm{~m} / \mathrm{s}$, the tunnel closed for all traffic (empty tunnel tube), the mechanical ventilation is completely shut down.

From the measurements [11] it is not clear how long an individual gust lasts, which is why three simulations were constructed with gust durations of $40 \mathrm{~s}(\mathrm{Sim} 1), 50 \mathrm{~s}(\mathrm{Sim} 2)$ and $60 \mathrm{~s}$ (Sim 3), which are the most common lengths of Bora wind gusts [9] and [10]. The results are presented in Table 1. The difference between the theoretical CFD models and real measurements from the tunnel is around $5 \%$, while almost being the same in certain cases (simulation 2). It is very difficult to postulate all parameters (gust characteristics, coefficients, losses, etc.) of a theoretical model that affect the air velocity in the tunnel. As the difference in results of the simulations and real measurements is about $5 \%$, the theoretical CFD models can be considered a very close approximation to a realistic situation. The other CFD models used in the research scenarios are based on the same assumptions, which is why we can claim that the deviations from a real situation are around 5 $\%$ too.

Table 1. Comparison of results from FDS simulations and real measurements [23] and [26] - model validation

\begin{tabular}{|c|c|c|c|c|}
\hline \multicolumn{5}{|c|}{$\begin{array}{l}\text { The speed of air movement in the tunnel tube under the influence of } \\
30 \mathrm{~m} / \mathrm{s} \text { gusty wind on the portal }\end{array}$} \\
\hline & $\begin{array}{l}\text { FDS } \\
\text { result } \\
{[\mathrm{m} / \mathrm{s}]} \\
\end{array}$ & $\begin{array}{c}\text { Kastelec tunnel } \\
\text { measurements } \\
{[\mathrm{m} / \mathrm{s}]}\end{array}$ & $\begin{array}{c}\text { Difference } \\
\text { in speed } \\
{[\mathrm{m} / \mathrm{s}]}\end{array}$ & $\begin{array}{c}\text { Difference } \\
{[\%]}\end{array}$ \\
\hline $\operatorname{Sim~1:40s}$ & -5.20 & -5.47 & 0.27 & 4.9 \\
\hline $\operatorname{Sim} 2: 50 \mathrm{~s}$ & -5.48 & -5.47 & 0.01 & 0.2 \\
\hline Sim 3: $60 \mathrm{~s}$ & -5.76 & -5.47 & 0.29 & 5.3 \\
\hline
\end{tabular}

\section{CONCLUSION}

Road tunnels are strategic structures for the transport of people and goods. Fire is very hazardous for tunnel users, and likewise for fire-fighters who attempt to extinguish the fire. A key element of safety for users and for a safe intervention is the adequate ventilation of tunnels, which must ensure the extraction of smoke and heat. When designing the ventilation system it is necessary to consider various factors, one of the more important factors being meteorological effects. A key meteorological factor that affects ventilation is wind. Wind, which blows on the portal of unidirectional road tunnels with longitudinal ventilation in the opposite direction of the traffic counteract the ventilation. Mechanical ventilation must provide a suitable air velocity in the tunnel to overcome friction and wind 
pressure exerted on the portal. It is important that the mechanical ventilation provides air velocity in the tunnel that is greater than the fire's critical velocity, which ranges from $1.5 \mathrm{~m} / \mathrm{s}$ for fires up to $10 \mathrm{MW}$, and up to $4 \mathrm{~m} / \mathrm{s}$ for fires over $100 \mathrm{MW}$. This article establishes the importance of taking into account the gustiness of winds when determining the adequate safety of road tunnels. As a case study, research of the Kastelec tunnel was carried out, in an area where the gusty wind of the Bora blows. Research has shown that the effect of gusty wind, such as the example of the Bora wind, on the speed in a tunnel differs from that of a constant wind. It is necessary to consider a gust's intensity, duration, and period of repetition. The velocity at the tunnel portal during the gust fluctuated depending on its curve. This effect also transfers to the movement of air in the tunnel. As the occurrence of the maximum speed of the gust is only short-term, followed by a period of low velocity wind, the mechanical ventilation air flow inertia prevents a greater drop in speed in the tunnel. By comparing the effect of constant wind, a significant difference between the wind velocities at which the tunnel air flow velocity is still adequate is determined. In all wind scenarios where the gusts were at $30 \mathrm{~m} / \mathrm{s}$, the ventilation velocity in the tunnel was adequate for the determined $10 \mathrm{MW}$ fire and provided the extraction of smoke from the tunnel. Theoretical CFD models of the effect of wind have been validated with real wind measurements in the area of the Kastelec tunnel [23] and measurements from the tunnel tube [26]. Verification indicated up to a $5 \%$ deviation in the results. On the basis of this, designed CFD models can be categorised as a good approximation of reality.

\section{ACKNOWLEDGEMENT}

Authors thank DARS d.d. The Motorway Company of the Republic of Slovenia, especially Mr. Marko Korošec for providing measurement [11] and [26] and Mr. Boris Milič who helped with other information about motorway tunnels in Slovenia.

\section{REFERENCES}

[1] Petelin, S., Vidmar, P., Perkovič, M., Paliska, D., Klasek, Z., Filli, B., Polman, Z., Čufer, A., Malovrh, M., Gerzevič, R., Resman, N., Rom, J. (2005). Fire Safety Field Research Paper: Success of an Intervention in Tunnels. Republic of Slovenia, Ministry of Defence. (in Slovene)

[2] Drakulič, M. (2006). The Role of the Longitudinal Ventilation System in Road Tunnel Fire Accidents. Doctoral dissertation, Faculty of Mechanical Engineering and Naval Architecture, Zagreb. (in Croatian)
[3] Tunnel Study Centre. (2003). Ventilation. Road Directorate, Pariz. (in French)

[4] Modic, J. (2003). A Model of a Tunnel and a Simulation of Ventilation in the Case of Fire. Strojniški vestnik - Journal of Mechanical Engineering, vol. 49, no. 9, p. 458-468.

[5] Rhodes, N. (2011). Operational Strategies for Emergency Ventilation. World Road Association - PIARC, Report no. $2011 R 2$.

[6] Suban, A. (2012). Analyses to Support Intervention in the Event of a Fire in Road Tunnel. M.Sc. Thesis, Faculty for Maritime Studies and Transport, University of Ljubljana, Portorož. (in Slovene)

[7] Wu, Y. (2010). The critical velocity and the Fire Development. Fourth International Symposium on Tunnel Safety and Security Frankfurt Conference Proceedings, p. 407-417.

[8] Rakovec, J., Žagar, M., Bertalanič, R., Cedilnik, J., Gregorič, G., Skok, G., Žagar, N. (2009). Winds in Slovenia. ZRC, Ljubljana. (in Slovene)

[9] Petkovšek, Z. (1987). Main bora gusts - a model explanation. Geofizika, vol. 4, p. 41-50.

[10] Perkovič, M., Batista, M., Najdovski, D., Vidmar, P., Luin, B.. (2011). Measuring the effect of crosswinds on dynamics of road vehicles, focussing on the Bora analyses. ICTS Portorož Conference proceedings.

[11] DARS (2014). Measurements of Bora wind on Smelavc viaduct (45 $\left.34^{\prime} 52.32^{\prime \prime} N, 13^{\circ} 54^{\prime} 34.60^{\prime \prime} E\right)$ - March 4 and March 5, 2014. Company database archive, Ljubljana.

[12] Muhasilovic, M., Duhovnik, J. (2012). CFD-Based Investigation of the Response of Mechanical Ventilation in the Case of Tunnel-Fire. Strojniški vestnik - Journal of Mechanical Engineering, vol. 58, no. 3, p. 183-190, Dol:10.5545/svjme.2009.091.

[13] Rahmani A., Carlotti P., Gay, B., Buffat, M. (2004). Simulating fires in tunnels using large eddy simulation. International Conference Tunnel Safety and Ventilation, Graz Conference Proceedings, p. 111-118.

[14] McGrattan, K., Hostikka, S., Floyd, J., Baum, H., Rehm, R., Mell, W., McDermott, R. (2010). Fire Dynamics Simulator (Version 5) Technical Reference Guide, Volume 1: Mathematical model. NIST/VTT, Department of Commerce, Washington.

[15] Weisenpacher, P., Halada, L., Glasa, J. (2011). Computer simulation of fire in a tunnel using parallel version of FDS. MCS7 Conference Proceedings.

[16] Yan-ling, L., Xin-feng, L., Ping, L. (2009). FDS analysis of smoke spreading in the tunnel with flue under fire. Journal of Chemistry \& Chemical Engineering, vol. 3, no. 4, p. 39-45.

[17] Huczek, J., Mintz., T., Bajwa, C., Das, K., Axler, K. (2010). FDS simulation of the newhall pass tunnel fire. $4^{\text {th }}$ International Symposium on Tunnel Safety and Security, Conference Proceedings.

[18] Kim, M.E. (2006). A Study on Pulsation in Runehamar Tunnel Fire Tests with Forced Longitudinal Ventilation. M.Sc. Thesis, Worcester Polytechnic Institute, Worcester.

[19] Li, Y.Z., Ingason, H., Lönnermark, A. (2012). Numerical simulation of Runehamar tunnel fire tests. $6^{\text {th }}$ International Conference Tunnel Safety and Ventilation. Conference Proceedings, p. 203-210. 
[20] McGrattan, K., Hostikka, S., McDermott, R., Floyd, J., Weinschenk, C., Overholt, K. (2014). Fire Dynamics Simulator Technical Reference Guide Volume 3: Validation. NIST/VTT, Department of Commerce, Washington.

[21] Smardz, P. (2006). Validation of Fire Dynamics Simulator (FDS) for Forced and Natural Convection Flows. M.Sc. Thesis, University of Ulster, Ulster.

[22] Nielsen, J.G. (2013). Validation Study of Fire Dynamics Simulator. M.Sc. Thesis, Department of Energy Technology, Aalborg University, Aalborg.
[23] Vidmar, P. (2007). Deterministic Model of Fire in Tunnel. Ph.D. Thesis, Faculty for Maritime Studies and Transport, University of Ljubljana, Portorož. (in Slovene)

[24] Kraut, B., Puhar, J., Stropnik, J. (2001). Kraut's Engineering Handbook, 13 th edition. Littera picta, Ljubljana.

[25] Vidmar, P., Petelin, S. (2003). An analysis of a fire resulting from a traffic accident. Strojniški vestnik - Journal of Mechanical Engineering, vol. 49, no. 5, p. 254-266.

[26] DARS (2014). Measurements in Kastelec tunnel tube - March 4 and March 5, 2014. Company database archive, Ljubljana. 